\title{
Activating whole brain innovation: A means of nourishing multiple intelligence in higher education
}

\author{
A-L DE BOER, PH DU TOIT AND T BOTHMA
}

\begin{abstract}
The interconnectedness of the constructs 'whole brain ${ }^{\oplus}$ thinking' and 'multiple intelligence' forms the epicentre of this article. We depart from the premise that when whole brain ${ }^{\infty}$ thinking is activated multiple intelligence can be nourished. When this becomes evident in a higher education practice it can be claimed that such a practice is innovative. Whole brain ${ }^{\oplus}$ thinking that informs intelligence and vice versa is inevitable when it comes to facilitating learning with a view to promoting quality learning in the context of higher education. If higher education is concerned about the expectations of industry and the world of work there is no other option as to prepare students in such a way that they develo as holistic - whole brained and intelligent - employers, employees and entrepreneurs who take responsibility for maximising their full potential. Becoming a self-regulated professional and being reflexive are some of the attributes of the $21^{\text {st }}$ century which should be cultivated in all students. Research on whole brain ${ }^{\oplus}$ thinking and multiple intelligence shows that these human attributes form an integral part of one's interaction with life - one's environment and especially people as integral part of the environment. This focus on people highlights the need for developing soft skills within every curriculum. The epistemological underpinning of our reporting of experience in practice and research of the application of the principals of the constructs is metareflective in nature. Instead of a typical traditional stance to research we do not report on the numerous sets of data obtained over a period of more than 15 years. Our approach is that of a meta-reflective narrative as most of the studies we were involved in and still are, are reflective as it is most often than not action research-driven. And action research is a reflective process. We report on evidence-based practice that includes fields of specialisation such as health sciences, engineering, academic staff development, financial sciences, teacher education and higher education. Important aspects of any higher education practice, such as curriculum development, facilitating of learning and assessment are addressed. Practice-based evidence of each, where applicable, is offered as claims of innovation.
\end{abstract}

Keywords: action research, higher education, meta-reflection, multiple intelligence, whole brain ${ }^{\varpi}$ thinking

\section{$1 \quad$ Introduction}

Nothing is quite as practical as a good theory (Van de Ven 1989:486)

The quotation from Van de Ven is relevant in terms of the research we undertake on a continual basis. We are of the opinion that what we do in our higher education practice informs theory. As new bodies of knowledge, based on our respective practices are constructed, and by engaging applicable literature and other scholars in the field, the current

$1 \quad$ Ann-Louise De Boer, University of Pretoria, E mail: ann-louise.deboer@up.ac.za (Corresponding author). Pieter $\mathrm{H}$ du Toit, University of Pretoria, E mail: pieter.dutoit@up.ac.za. Theo Bothma, University of Pretoria, Email: theo.bothma@up.ac.za.

TD The Journal for Transdisciplinary Research in Southern Africa, 11(2) November 2015, Special edition: Reenchantment pp. 55-72. 
body of knowledge on innovation in higher education is expanded and enriched. In this regard Kumar (2014) mentions the importance of increasing understanding of one's own profession and advancing the professional knowledge base. Therefore we apply the principles of a 'good theory', namely whole brain ${ }^{\circledast}$ thinking (Herrmann 1995; 1996) in practice. This application has been well researched and documented and the outcome informs the theory in a reciprocal manner.

Our constructivist approach includes scholarly reflection (Fringe 2012). This article is written in the form of a meta-reflective narrative as we reflect on our reflection (Wolvaardt \& Du Toit 2015). The narrative is also auto-ethnographic (O'Leary 2014; Du Toit 2013; Du Toit $2014 \mathrm{a} / \mathrm{b}$ ) in nature as we as researchers are the primary and active participants and we are not passive in making meaning. This level of our reflection includes the contribution to our scholarly understanding of the link between multiple intelligences (Gardner 1993) and whole brain $^{\circledast}$ (Herrmann 1995; 1996) innovation in teaching practice - the two main theories that inform our research and practice. However, since higher education is multifaceted, we acknowledge the fact that other learning theories are to be integrated in order to form a holistic view of practice. Such theories include self-regulated learning (Hugo, Slabbert, Louw, Marcus, Bac, Du Toit \& Sandars 2012), cooperative learning (Hugo et al. 2012) and blended learning (Herrmann-Nehdi 2012). However, we do not discuss each as part of a theoretical framework but address them throughout our reflection where appropriate - it is rather used as a golden conceptual thread that is woven throughout our reflection. As in traditional research we do not report extensively on the numerous sets of quantitative and qualitative data that have been gathered over more than a decade of our research on innovation in higher education - therefore the narrative approach.

Our investigation of the application of the principles of whole brain ${ }^{\circledR}$ thinking in higher education (De Boer, Du Toit, Scheepers \& Bothma 2013) specifically concerning teaching practice, forms the ontological premise from which we depart. Every individual has his or her own thinking preferences in approaching and executing tasks. This is true for students as well as lecturers. In this article we report evidence of whole brain ${ }^{\varpi}$ innovation in higher education practice.

The rationale for innovation is to be found, inter alia, in the expectations of the world of work - real life. Academic attributes of the student of the $21^{\text {st }}$ century are to be kept in mind. These include innovative thinking, problem-solving skills, teamwork, communication skills, critical reflection, and entrepreneurial and leadership skills.

Our conceptual framework informs the philosophy that enriched our work in the past and still does. The principal construct is whole brain ${ }^{\circledast}$ thinking (Herrmann 1995; 1996) that forms the epicentre of our respective teaching practices and the research we do. The construct is advocated in our scholarly encounters with our peers. We use it to activate whole brain ${ }^{\varpi}$ innovation and consider it an educational value - a value that has an impact on our work and the work of our peers. As the title of this article suggests, it is this activation of innovation that nourishes intelligence in higher education. Throughout our research journeys in the context of higher education we have gathered numerous examples of where whole brain ${ }^{\varpi}$ innovation was activated and where our peers embarked on innovative ways to enhance intelligence of all sorts in their students (Du Toit 2012) with a view to enhancing the quality of learning. The whole brain ${ }^{\circledast}$ model (Herrmann 1995) encompasses of all human behaviour. Any task to be executed can be linked to any of the dimensions of the model as it is a metaphorical representation of the brain - and the brain monitors the entire human capacity. 
Maximising the full potential (Slabbert, De Kock \& Hattingh 2009) of our peers, their students and ourselves forms part of our value-driven engagement of our daily encounters with scholars and students.

Our scholarly engagement with life in general and research in particular is constructivist in nature. Therefore we would like to contribute to our understanding of intelligence as a holistic entity and would suggest the constructing of 'whole brain intelligence' as an umbrella term for all theories of intelligence, from emotional intelligence (Bradberry \& Greeves 2009), transcendental intelligence (Slabbert et al. 2009) to multiple intelligence (Gardner 1993). We return to this claim in the concluding section of this article.

Herrmann, acknowledged in literature as the father of brain dominance technology (Morris 2006), focused his initial research on understanding how the creativity of the human brain is unleashed. His valuable contribution involves his documentation of the fact that the human brain comprises four distinct learning modes and not only two hemispheres, where each of the modes has its own ways of processing information and functioning (Herrmann 1995).

Herrmann's research led to the development of a scientifically validated instrument that can quantify the degree of thinking preferences for specific modes within the whole brain ${ }^{\varpi}$ model. The Herrmann Brain Dominance Instrument $\left(\mathrm{HBDI}^{\oplus}\right)$ is a questionnaire consisting of 120 items that quantify thinking preferences. The results of the questionnaire are a visual plot of the thinking preferences of the individual. A HBDI ${ }^{\circledast}$ profile provides scientifically validated information to understand one's own learning strengths and learning avoidances (Herrmann 1995). However, it should be mentioned that the instrument does not measure competencies but thinking preferences.

In order to understand the profile, it is important to explain the quadrants and modes of thinking briefly (See Figure 1).

Based on our research and by extending the Herrmann (1995) model, a comprehensive whole brain model was designed (De Boer et al. 2013). This metaphorical model represents the four different quadrants (A, B, C and D) Herrmann (1995) identified. The focus of the A quadrant is on logical, rational, quantitative and theoretical thinking (What?). B quadrant thinking entails organising, and sequential and methodological approaches to execute tasks (How?). The focus of the $\mathrm{C}$ quadrant is on emotional, expressive, interpersonal and kinaesthetic aspects of emotive thinking (Who?). D quadrant thinking is about visual, experimental, simultaneous and conceptual ways of thinking (Why?).

Each quadrant represents specific thinking preferences. The A quadrant focuses, inter alia, on analysing, theorising, logical processing and quantifying. Preferences of the B quadrant include organising, sequencing and practising. The $\mathrm{C}$ quadrant includes sharing, internalising, moving, feeling and involving. Exploring, discovering, conceptualising and synthesising are typical of the D quadrant.

When an individual displays a preference for a specific quadrant(s), an avoidance of another might be displayed. Such avoidances usually become present in tasks that one struggles with when not using part of one's preferred mode of thinking. Individuals - in our context lecturers and students - with a preference for A quadrant thinking struggle with vagueness, expressing emotions, imprecise concepts and ideas and a lack of logic. Lecturers and students who prefer B quadrant thinking typically struggle with taking risks, unclear concepts and instructions, and ambiguity. C quadrant thinkers struggle with too much data and analysis, lack of interaction and time for relationships while an individual with a preference for $\mathrm{D}$ 
quadrant thinking struggles with autocratic excessive strictness, time management, lack of flexibility and too much detail.

The figure below is a visual representation of the above.

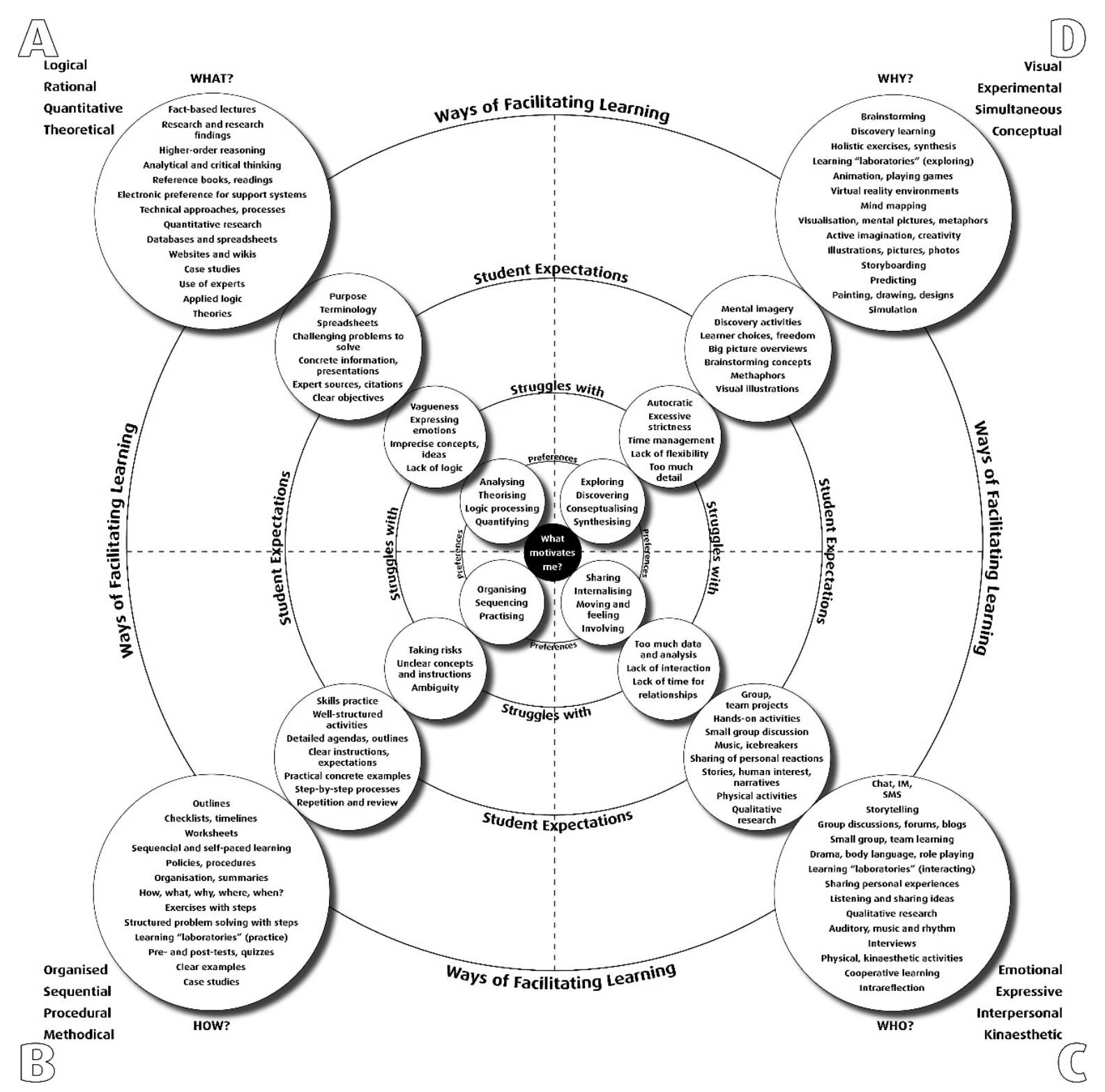

Figure 1: Comprehensive whole brain model (De Boer et al. 2013)

It is clear from the model that for each of the modes of thinking there are expectations and ways of facilitating learning from and for a specific quadrant.

As no single learning theory can be implemented successfully in isolation, we integrate the multiple intelligences theory of Gardner (1993) into the different quadrants of the whole brain ${ }^{\circledast}$ model. The lecturer should realise that he or she also has to take part in the renaissance in higher education. It is the individual, and not the education institution that should initiate, implement and nurture the new paradigm. 
Every student and every lecturer is created with unique, unlimited potential. All lecturers should create opportunities by which a student's potential can be rediscovered and developed to the full through a quest for lifelong learning.

Learning brings about change. Change means growth, and growth is a continuous process for as long as we live. Sometimes learning is intentional, sometimes incidental. Characteristics of deep learning are exploring, discovering and experimenting. In order to construct meaning, productive learning should be promoted. The unknown, typical of the current world of work, urges us to focus on productive and creative thinking instead of reproducing learned knowledge.

The unknown brings about uncertainties and therefore asks for creativity in all aspects of life - including education and learning. Part of rediscovering creativity in humans means, inter alia, that both the lecturer and student need to become versatile and whole brain ${ }^{\circledast}$ partners. In this respect Gardner's (1993) studies refer to the eight different types of intelligence that should be developed.

We acknowledge that quite a number of other scholars have published on intelligence and identified an array of intelligences. However, we list the following as core intelligences:

- Logical-mathematic intelligence: The familiar kind of intelligence associated with problem-solving - as the non-verbal ability to make (logical) causal conclusions that may involve mathematical calculations.

- Linguistic intelligence: It constitutes the ability to perceive, interpret and produce language as verbal functions.

Traditionally only these two intelligences were selected and used to describe an individual's IQ. This practice completely neglected the functions of the right hemisphere of the brain, consisting of the following intelligences:

- Musical intelligence: The ability to perceive, appreciate and produce music.

- Bodily-kinaesthetic intelligence: The ability to control body movement to solve problems or to create a product using the whole body, or parts of it.

- Spatial intelligence: Perceiving or constructing a mental model of a spatial world and to manoeuvre and apply the model.

- Interpersonal intelligence: The ability to relate to others and cooperate in social interaction.

- Intrapersonal intelligence: The function here is the control of the perception, interpretation and production of intra-subjective relationship (with and regarding the self).

- Naturalistic intelligence: This entails all activities related to positive interactions with nature.

Multiple intelligence should become an integral part of any learning opportunity - both in the case of an individual learner and a group. In a group each member will contribute in terms of latent potential and intelligence and in complementing others' intelligences.

\section{Evidence of innovation}

The exemplars that we report on cover a wide range of fields of specialisation, such as health sciences, engineering, information management, higher education and financial science. These exemplars are mainly from the University of Pretoria. However, based on our 
experience in practice, application and research beyond the borders of South Africa, we refer to research studies from a European context and another from an African context. It should be noted that different fields of specialisation do attempt to develop curricula that would prepare students for the unknown future (Slabbert et al. 2009).

Consequently the practical application of the principles of whole brain ${ }^{\circledast}$ thinking in different fields of specialisation is indicated. The applications include facilitating of learning, assessment and curriculum development.

\subsection{Health Sciences}

Lumsdaine and Lumsdaine (1995) report the following:

It is becoming clear that creativity and teamwork act synergistically - both have to be developed systematically and simultaneously for students to achieve improved learning and problem-solving outcomes.

In the School of Dentistry a lecturer embarked on a whole brain ${ }^{\oplus}$ learning journey with his students. The aim on the one hand was to stimulate innovative ideas and on the other to enhance cooperative learning while mastering the factual and detailed information that constitutes the subject content. This was achieved by introducing group work activities for the first time (promoting $\mathrm{C}$ quadrant thinking and stimulating interpersonal intelligence). It not only resulted in better dialogue between the lecturer and the students, but also among the students themselves. Interactive discussions were now taking place throughout the sessions. The implications of whole brain thinking on practice are evident in the change in the lecturer's style of facilitating learning.

The application of the principles of whole brain ${ }^{\circledR}$ thinking informed the lecturer's assessment practice. The lecturer incorporated whole brain assessment opportunities in support of the whole brain ${ }^{\circledast}$ approach to teaching practice. During the formative assessments facts and detail of the module content is normally assessed, requiring mainly $\mathrm{A}$ and $\mathrm{B}$ quadrant thinking, thus stimulating logical intelligence. In order to stimulate $\mathrm{C}$ and $\mathrm{D}$ quadrant thinking he included self- and peer assessments during learning opportunities ( $\mathrm{C}$ quadrant thinking; respectively intra- and interpersonal intelligence). Finally he expected students to be able to synthesise relevant subject knowledge within a clinical setting when answering questions requiring D quadrant thinking (Oosthuizen 2001) and incorporating spatial intelligence.

The final changes incorporated into the assessments were whole brain ${ }^{\circledast}$ summative evaluation. This was achieved by including a project and a final test at the end of the series of learning opportunities. The students were required to produce, manufacture or create the entire module content of Tooth Morphology as a visual presentation and present it to the rest of the class. The facts needed to be accurate (A quadrant thinking), the details needed to be evident (B quadrant thinking), the freedom to choose either to work as an individual or as a member of a group was given ( $\mathrm{C}$ quadrant thinking; respectively intra- and interpersonal intelligence), while the final criteria for the project focused on integrating the entire curriculum in a visual format ( $\mathrm{D}$ quadrant thinking). All the outcomes of the project would promote whole brain ${ }^{\varpi}$ thinking and embrace multiple intelligence.

While the students were completing their projects they became highly motivated and it was interesting to note that some preferred starting with the big picture first, and then breaking it down to detail. Others started with the detail and then constructed the big picture. The different products designed provided even more evidence of the diversity of the students' 
thinking, their commitment and willingness to embrace the difference. Similar findings from student projects are reported on by Lumsdaine and Lumsdaine (1995).

The results indicated that the students unleashed their creativity, and artefacts ranging from games, an in-flight magazine and a painted clinical jacket to a family album to name but a few, illustrated not only their mastery of the subject content but also the ability to construct new knowledge in a meaningful way (Oosthuizen 2001).

When the final marks for the module were compiled, the students on average performed 30 percent better than in previous years. The improvement was remarkable. The average grade improved from 62 percent to 92 percent. Their experience of the whole brain ${ }^{\circledR}$ nature of the curriculum, the conducive learning environment the lecturer created, the creative whole brain $^{\varpi}$ assessment opportunities were all features that not only motivated the students but led to exceptional academic achievements.

Only recently an action research project was commenced by the Department of Family Medicine. Several workshops on whole brain ${ }^{\circledR}$ learning have been conducted for lecturers and students. The workshops for lecturers form part of a series of workshops focusing on educational professional development. The workshop on whole brain ${ }^{\circledR}$ learning is offered to first-year students annually. It is done with the aim to introduce whole brain ${ }^{\circledR}$ learning and to prepare them for the programme as the programme includes whole brain ${ }^{\varpi}$ learning, among other learning theories, such as self-regulated and constructivist learning. The learning setting is authentic and patient-centred as real-life problems need to be solved in clinical situations. The practical application of the principles of whole brain ${ }^{\circledast}$ thinking informed the entire curriculum - from the design and implementation phase, facilitating of learning and the assessment of learning. Regarding the educational professional development of staff involved in the offering of the programme the principles were applied during professional development sessions with staff.

The composite brain profile of the lecturers involved in offering the programme, represents thinking preferences in all four quadrants and a balanced distribution within the four quadrants. However, the preference map reveals the least preferred thinking preference to be for A quadrant thinking. Some of the individuals had a very strong preference for $\mathrm{D}$ quadrant thinking. This may be one of the reasons for the group being innovative in what they do when it comes to designing and implementing the curriculum. This innovation was documented by Hugo et al. (2012).

\subsection{Engineering}

The practical application of the principles of whole brain ${ }^{\circledast}$ thinking informed curriculum design and development activities in different fields of engineering. Next it is outlined how this practical application is linked to curriculum development in engineering.

Herrmann (1996) points out that innovative thinking (D quadrant) can and has been achieved through curriculum changes. Research spanning more than thirty years indicates that thinking preferences of individuals are distributed across all four quadrants, provided the group is large enough (Herrmann 1996).

The Department of Civil Engineering was the first department to act on the much needed lack of innovative thinking and soft skills in the curriculum that was evident from widely published research articles (Horak, Steyn \& De Boer 2001; Liebenberg \& Matthews 2012; Lumsdaine, Lumsdaine \& Shellnut 1999). 
Lecturers of the Department designed a module for all first-year students, namely Innovation 101. The purpose of the module was to create a platform for incorporating the much needed soft and innovative skills. They started by assessing not only the thinking preferences of the students but also those of the lecturers to determine to what extent there was an alignment. The results showed dominance in both students and lecturers for a stronger preference for $\mathrm{A}$ and $\mathrm{B}$ quadrant thinking relating to logic-mathematical intelligence. Similar findings were documented by Lumsdaine et al. (1999). However, should both groups evaluated be large enough, they concluded that the current curricula would not adequately cater for all students' needs, especially students who have a preference for $\mathrm{D}$ and $\mathrm{C}$ quadrant thinking - those more inclined to favouring intra- and interpersonal intelligence. The lecturers admitted that they needed to make the first shift in thinking by embracing the notion of multiple intelligence and whole brain ${ }^{\oplus}$ thinking, and then master these softer skills as an ongoing process within the curriculum. The module on innovation designed afforded them the opportunity to do so.

The first step was to work in diverse groups. Selection of diversity was done on the basis of their individual $\mathrm{HBDI}^{\circledast}$ results. Students were given a group assignment and the necessary tools for creative problem-solving and were asked to execute the task by using the different mind-sets (whole brain ${ }^{\oplus}$ thinking) promulgated by Lumsdaine and Binks (2005) and (Herrmann 1995). ' The process they had to follow was to identify the problem, to generate possible solutions, to ensure they get buy-in from all the participants and to monitor and evaluate the project. They then had to present their project to the entire group.

The project afforded them the opportunity of developing whole brain ${ }^{\varpi}$ strategies in all four of the quadrants and activating multiple intelligence. They reported that the project initially was a challenge as everybody pulled in different directions - wanted to have it their individual way. However, once they understood and valued the group dynamics and the different ways of thinking individuals had brought to the project, the end result was much better than what they originally anticipated. They reported that for them it was what the world of work requires of you - not only to have specialist knowledge but be competent to work in groups and teams and display proficiency in all of the aspects of whole brain ${ }^{\varpi}$ thinking. No engineer, or any professional for that matter, can afford to work on his or her own - they need to work in teams and groups, displaying interpersonal intelligence associated with $\mathrm{C}$ quadrant thinking.

The Department of Mining Engineering also decided to address the gap between the objective technical nature of the existing curriculum and the demands of industry by incorporating more soft skills within the curriculum. Those responsible for curriculum planning created the Innovation in Mining Design module within the final year curriculum to address the ideas proposed and supported by Pulko and Parikh (2003), namely to be able to work effectively within teams (interpersonal intelligence supported by $\mathrm{C}$ quadrant thinking). In the past the emphasis was on mainly understanding concepts (translated into engineering terms as hard skills) associated with $\mathrm{A}$ and $\mathrm{B}$ quadrant thinking, thereby stimulating logical and mathematical intelligences. They realised that introducing an innovation design module would afford them the opportunity to address the softer skills required by $\mathrm{C}$ and $\mathrm{D}$ quadrant thinking. Lumsdaine et al. (1999) and Lumsdaine and Lumsdaine (1995) advocate creative problem-solving in engineering design as a soft skill that needs greater emphasis in the curriculum. The Innovation in Mining Design module was developed to enhance collaborative learning and to promote working effectively in teams. 
For the past few years all final year mining students have been profiled by means of the $\mathrm{HBDI}^{\circledast}$ and learning tasks are designed to enhance teamwork. They are also afforded the opportunity to discuss up front possible implications for their projects and overall performance of the group during allocated time (Knobbs 2011) (A and C quadrant thinking). The Department adopted the model and facilitate learning in such a way that students learn how to participate in diverse teams to develop the different mind-sets required to solve problems creatively. As Lumsdaine and Binks (2005) propose, this requires the thinking skills associated with all four quadrants of the whole brain model (Herrmann 1995; 1996).

Lumsdaine and Binks (2005) promulgate different mind-sets for different phases in creative problem-solving. Students need to learn that the first step in creative problem-solving is 'problem identification'. In this phase the mind-set of the 'detector' (A and B quadrant thinking) - looking for clues, asking questions - is important. Nothing can be overlooked or not be analysed. The skills of the detector are to analyse everything and to look at the whole (D quadrant thinking). Opportunities need to be discovered that will enable students to find the root cause to define the problem. The shift now is to look through the lens of the 'explorer' (D quadrant thinking).

In generating possible solutions, the thinking requirements are for the $\mathrm{C}$ and $\mathrm{D}$ quadrants. Generating is associated with the imagination, intuitive ideas and concepts, long-term solutions and futuristic thinking - or as Lumsdaine and Binks (2005) metaphorically illustrate - the mind-set of the 'artist'. Students then need to learn how to brainstorm, they are encouraged to think outside the box and paint the canvas as required by the artist. They need to synthesise all their ideas that they have generated and to do this they need to switch to the mind-set of the 'engineer'. This typically requires A and B quadrant thinking. In evaluating the best idea they need to adopt the mind-set of the 'judge' and this requires the application of $\mathrm{A}$ and $\mathrm{B}$ quadrant thinking. The last mind-set they need to adopt is that of the 'producer' - the one pulling everything together, primarily focusing on $\mathrm{C}$ and $\mathrm{B}$ quadrant thinking to complete the project successfully.

There is no single intelligence or thinking preference that can be operationalised in isolation; neither is the one better than the other. In order to solve problems creatively, communicate effectively, work in teams, we need all four modes and apply multiple intelligence to work together in synergy with a view to finding the best solution.

Encouraging collaborative learning and opening up to other students on a personal level were of the biggest challenges the lecturers had to overcome. Moving the focus away from individual learning to group learning was difficult at first and met with resistance. However, through engagement and building trust relationships with the lecturer, students actually expressed their appreciation for the new way of facilitating learning.

It is of significance to mention that the lecturer responsible for the module is a senior lecturer with vast industry experience, holding not only an engineering degree, but also degrees in commerce, leadership and psychology - most probably a typical academic make-up of a whole brain $^{\oplus}$ facilitator of learning. He became more of a mentor empowering students to find alternative solutions to problems that turned up during contact sessions.

To continue on the journey of innovation, the Department appointed a part-time instructional designer to start changing the existing learning material, which reflected a preference for stimulating A quadrant thinking. The change was brought about in support of a more blended (whole brain ${ }^{\oplus}$ ) approach. Quality visual material, real-time video-clips and 
animations are continually designed or acquired by the lecturing team to facilitate students' understanding of difficult concepts. The mind shift that students had to make was achieved through activating innovative thinking with a view to nourishing interpersonal intelligence.

\subsection{Information management}

Initiatives of the Department of Information Science were built on the experiences of colleagues in the application of whole brain ${ }^{\varpi}$ facilitating of learning as reported in numerous research publications of the past 14 years. The research publications gave impetus to ensuring that the curriculum offered to students remains relevant and aligned with what is needed in the industry, especially when it comes to competence in information management.

Insights that lecturers gained from understanding their own thinking preferences allowed them to embrace facilitating learning in a whole brain ${ }^{\circledR}$ fashion. They realised the need for a blended learning approach as students are knowledgeable in using technology such as Kindle, Google, UPLS, Twitter and other social media platforms to search for relevant information. Not only did they support blended learning but they also revised the prescribed textbook to include all quadrants with a view to promoting whole brain ${ }^{\circledR}$ learning.

The innovation is all the more visible when it comes to assessment practice. A collective effort to look at assessing students in a way that supports whole brain ${ }^{\otimes}$ thinking is essential because each class represents a whole brain ${ }^{\circledast}$ (Herrmann 1996). Formative assessment opportunities that promote whole brain ${ }^{\circledast}$ thinking that contribute to the final assessment mark of students enhance student motivation. Regular feedback on students' progress motivates them to engage in quality learning.

Keller's (1987) motivational model suggests that students' motivation can be enhanced by means of modules that capture their interest. A YouTube video to illustrate the information explosion and the importance of being competent in finding one's own way through the overload of information available was selected to capture their interest. The video illustrates the uncertainty of the environment in which they had to find their way; it contained precise facts and statistics on information growth (A quadrant thinking). The YouTube video specifically provided the overview (big picture) why students should acquire information management skills (D quadrant thinking) and highlighted the importance of knowing where to search for relevant information (B quadrant thinking); the music used in the video stimulated $\mathrm{C}$ quadrant thinking.

To enhance group work and understand the rationale for attending the compulsory module, students were given a group task instructing them to search for an article. They were given the freedom of selecting the search engine or database of their choice. The article was purposefully selected so that it could not be found with their current information management skills like Google Scholar. As a result they realised that the module was a necessity if they wanted to succeed in executing tasks for which they needed to search for information.

In order to activate interpersonal and spatial intelligence in a technological field, games were designed, stimulating A, B, C and D quadrant thinking at the same time. The purpose was to create an environment that stimulates interaction and creativity as well as to provide the essential facts the students had to learn. Student confidence can be enhanced on a regular basis through a sense of achievement. Games were introduced with a view to mastering the necessary vocabulary of the subject (A quadrant) while the students worked interactively also 
in groups ( $\mathrm{C}$ quadrant). The games included interactive cross-word puzzles, flash cards and hangman exercises, pick the correct letter, fill in the blank spaces or word, or matching the word and cartoon stories demonstrating real-life situations. The games gave immediate feedback to students regarding their progress. The games were subsequently uploaded onto the learning management system of the University in order to offer students the opportunity to access them should they wanted to revisit them. Although games are typical of the D quadrant the purpose was to enhance vocabulary by means of blended learning. Challenging concepts that are difficult to understand were identified and used to inform the games and selection of other media. Because concepts commonly fall within the A quadrant and are often displayed as bulleted lists visuals and animations were included to facilitate students' grasping of concepts. From the above the practical application of the principles of whole brain $^{\oplus}$ thinking is evident in curriculum development, facilitating of learning and assessment of learning.

\subsection{Educational professional development of lecturers}

\subsubsection{University of Pretoria}

Educational professional development at the University of Pretoria entails obtaining a formal qualification and attending a series of informal workshops. In the Faculty of Education an initiative to change the formal education qualification curriculum in higher education for lecturers significantly, the Postgraduate Certificate in Higher Education (PGCHE) introduced bold innovations. The initiative came from the programme coordinator whose whole brain ${ }^{\varpi}$ profile indicated an extreme preference for $\mathrm{C}$ and $\mathrm{D}$ quadrant thinking, a low preference for the $\mathrm{B}$ quadrant and almost an aversion to the A quadrant. While this was his preferred style of executing tasks, competence associated with all the quadrants is evident in his numerous publications that reflect a whole brain ${ }^{\circledast}$ approach to scholarship - one of the essential roles of lecturers to be enacted. An action research process was followed, ensuring continuous change - resembling the notion of living theory (McNiff \& Whitehead 2006).

The programme modules are now integrated in order to reflect the multidimensional and integrated nature of any higher education practice. This multidimensionality necessitates multiple scholarship such as scholarship of teaching and learning, research scholarship and scholarship of engagement. The core of the modules revolves around the activation of innovation and nourishing of all of the intelligences - in essence creative thinking in terms of all aspects and theories pertaining to teaching practice.

In the context of the PGCHE programme constructivist thinking is considered a whole brain $^{\circledast}$ approach to creative thinking and problem-solving. Lecturers and students form communities of practice - with $\mathrm{C}$ quadrant preferences and interpersonal intelligence as dominant aspects - that share the important responsibility they have in terms of scholarship of innovative higher education practice and the whole brain ${ }^{\circledast}$ constructivist epistemology (Du Toit 2012) in their respective practices. Students are expected to become innovative and visionary practitioners - scholars who would introduce competencies relevant to the world of work in their respective modules; scholars who would apply the principles of whole brain ${ }^{\varpi}$ learning, constructivist learning, self-regulated learning and multiple intelligence among others (Du Toit 2015).

Since the students are expected to provide evidence of claims of innovation in their respective practices based on the principles of living theory, innovation is continually activated in a selfregulated fashion. In this regard it can be said that intrapersonal intelligence is the key - 
notwithstanding the fact that self-regulated learning is a whole brain ${ }^{\varpi}$ act and involves all intelligences.

We agree with Proctor (2010:33) regarding creative problem-solving:

If there is a tendency for someone to argue that they have always done something in one particular way and that has always worked, it suggests that they are not open to new ideas that their own particular values dominate the way in which they tackle problems.

This supports our plea for becoming a whole brain ${ }^{\oplus}$ problem-solver who is willing not only to approach a problem from his or her preferred thinking preferences but to activate other modes of thinking and develop dexterity in all quadrants.

As communities of practice are activated, peer mentoring (De Jager 2011) becomes an integral part of the professional development of all involved. An innovative approach is followed when it comes to peer mentoring. It becomes an enriching reciprocal learning experience for everyone participating since the different thinking styles of the individuals concerned are involved and utilised. The importance of self- and peer assessment in team work - or cooperative learning - becomes evident. In the context of the programme team work is seen as participative action research (Zuber-Skerritt 2000). See Figure 2 in this regard.

As action research promotes reflection and is considered practitioner-research (McNiff \& Whitehead 2006) intrapersonal intelligence and the intrapersonal aspect of $\mathrm{C}$ quadrant thinking preferences are essential ingredients of the reflection process. We would like to iterate that action research does not apply to practitioners in the field of education only but to all professionals. Action research can, for example, be executed by the engineering or medical fraternity or practitioners in financial contexts. This is evident in the Department of Taxation and Department of Family Medicine reported on in this article as they embarked on smallscale action research projects to monitor innovation initiatives in their respective contexts.

Apart from having other attributes, action research is creative. When a creative learning approach is employed it is likely that innovative thinking will be promoted and intelligence be nourished. The approach enhances the quality of facilitating learning and learning per se. Slabbert et al. (2009) appeal for the enhancing of quality learning - ensuring that learning is authentic and would meet the demands of real-life situations.

The claim made, namely that the PGCHE promotes innovative thinking, can be justified by looking into the many examples of qualitative data obtained. A number of data sets of this kind are to be found in the outputs students generate, such as portfolios, draft articles and conference papers that serve as options for the final examination assignment. These outputs contain the documenting of the outcome of their respective action research projects they had to execute in the course of the year. As this examination assignment serves as a final summative assessment opportunity, it is authentic and reflects whole brain ${ }^{\circledast}$ scholarly thinking in all its dimensions.

In his final conclusion Du Toit (2012) confirms the claims that he makes about the value of the programme. Firstly, his students actually apply in their respective practices the principles of the theories they engaged with during the PGCHE. Secondly, his students manage to sustain the construction of new meaning in higher education theory more often than not, through a collaborative effort. This is evident from the large number of conference papers presented in most cases as co-authors. The visionary action research model executed by scholarly communities of practice represented in Figure 2 is applicable in this context. 
Informal educational professional development opportunities at the University also exist. They come in the form of tailor-made workshops and education innovation sessions. The latter are to be attended as a compulsory event within one's probation period when newly appointed. They are offered by the Department for Education Innovation. An array of topics such as assessment, blended learning and whole brain ${ }^{\varpi}$ facilitating of learning is addressed. The education innovation workshop that was offered for the duration of a week in the past and recently shortened to a two-day session is followed up by different educational consultants who each takes responsibility for the educational professional development within a faculty. The follow-up sessions include feedback sessions during which lecturers who attended the workshop report on their implementation of the learning theories that had been addressed. More often than not they offer feedback on how they have implemented whole brain ${ }^{\circledast}$ learning.

Evidence of innovation of practice is rewarded by the Department. Annually an education innovation award 'competition' is organised. The most recent recipient of the Laureate Award is a lecturer from the Department of Taxation who was mentored by the coordinator of the PGCHE. She reported her innovative ideas in a scholarly way (Van Oordt, Van Oordt \& Du Toit 2014) and that is exactly what we work towards - bridging the gap between scholarship of teaching and scholarship of research. The significance of the role of peer mentoring in the informal educational professional development of academic staff has been highlighted. With a view to promoting innovative facilitating of learning at the University a priority programme organised by the Department of Teaching and Learning, which resides under the auspices of the Directorate Human Resources is offered by the coordinator of the PGCHE. The programme revolves around the contribution whole brain ${ }^{\circledast}$ thinking brings to any teaching practice.

\subsubsection{University of Eduardo Mondlane}

We would like to reflect on the innovation at the Eduardo Mondlane University as it is an example of approaching academic staff development beyond the confines of traditional workshop formats. The core of the conceptual framework was an integration between whole brain ${ }^{\circledast}$ learning, self-regulated learning, peer mentoring and action research. The constructivist epistemology followed led to new meaning making of these constructs, such as 'whole brain ${ }^{\circledast}$ peer mentoring', 'whole brain ${ }^{\circledast}$ action research' and 'whole brain ${ }^{\circledast}$ self-regulated learning' (Du Toit 2012).

Academic staff members were offered the opportunity to engage in action research-driven peer mentoring initiatives. The principal mentor is one of the members of the academic staff and was intrigued to such an extent by whole brain ${ }^{\varpi}$ learning and action research that he designed his workshops around these constructs. For him it was imperative to involve his colleagues in such a way that they bought into the whole idea of applying the principles of whole brain ${ }^{\otimes}$ learning in their respective practices and to monitor the application by means of action research. The whole brain ${ }^{\circledast}$ profile of the principal mentor who facilitated the project was determined as well as those of all participating peers. It is of interest to note that the profile of the facilitator showed an inclination towards the A and B quadrant. However, during the execution of the project he showed willingness to act as a role model to his colleagues and implemented an array of means for professional learning. They, for example, had to present their proposed action research projects and had to draw visuals of what they intended to do while he gathered qualitative feedback, which included photo evidence. The visuals, photographs and willingness to work with others as a team relate to respectively the $\mathrm{D}$ and $\mathrm{C}$ quadrant, and spatial and interpersonal intelligence. In this way he was open to 
developing modes of thinking in the $\mathrm{C}$ and $\mathrm{D}$ quadrant for which he initially displayed an avoidance.

The initiative established a scholarly community of practice as the group of peers adopted a scholarly approach to teaching practice. Their unit of analysis (Mouton 2001) became whole brain ${ }^{\circledast}$ learning. Innovation in terms of contributing to the scholarship of action research is evident in the whole brain ${ }^{\circledast}$ action research model that was developed and implemented. It reflects the community of scholars that was formed and shows the multidimensional nature of participatory action research. In addition they created own living theory as McNiff and Whitehead (2006) proposes.

The figure below is a visual representation of the action research project.

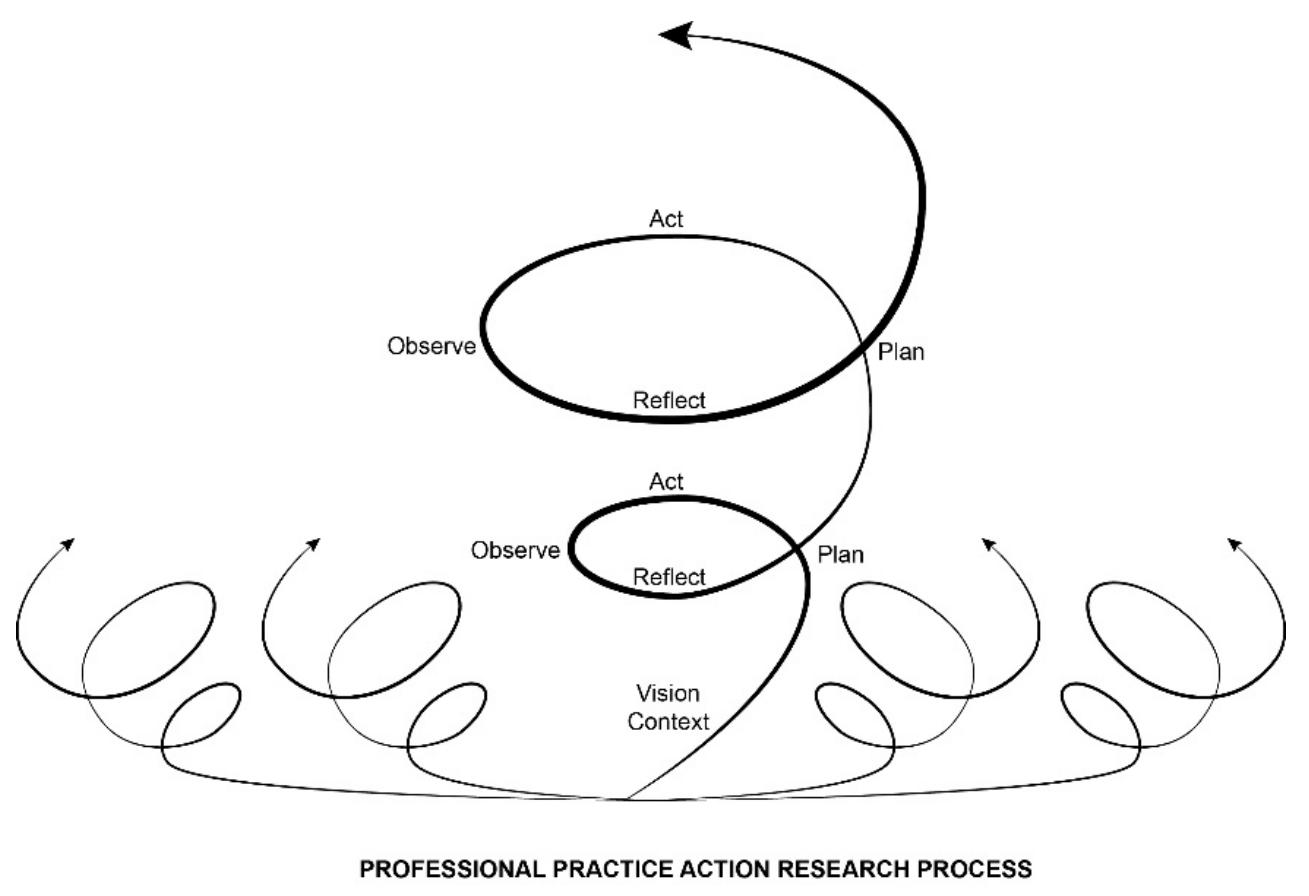

\section{Figure 2: Visionary action research model executed by a scholarly community of practice (Fringe 2012)}

The nature of the action research model executed by the visionary scholarly community of practice in question is a multidimensional cyclical process consisting of several spirals, each consisting of different cycles. Each cycle in turn has its own steps to be taken. These are executed in the context of a specific teaching practice. The following steps give direction to the implementation of a novel idea such as whole brain ${ }^{\circledR}$ learning: plan for whole brain ${ }^{\varpi}$ innovation; act by implementing the plan; observe by obtaining feedback from students and peers and using the principles of self- and peer assessment; reflect on the feedback, assessment and implementation and evaluate the process in order to re-plan and start a new cycle.

Evidence of the scholarly output of this project includes a completed $\mathrm{PhD}$ study and numerous conference papers. 


\subsubsection{Initiative at the University of Antwerp}

At the University of Antwerp in Belgium a module of the teacher education programme was enriched, using the principles of whole brain ${ }^{\circledast}$ facilitating of learning. This was necessitated as innovation became a focal point in the module - embracing the new paradigm in education (Slabbert et al. 2009). The module was aligned with the much needed competencies any lecturer or prospective student should master as value-adding attributes of professionals in any education setting. These include learning how to think (meta-cognition) creatively and critically, visionary thinking, lifelong learning and gaining insight into the entire work context. While these attributes were expected to be displayed by the students enrolled for the module, the lecturers had to act as role models in this regard.

It was a small-scale intervention as it involved only 32 students, three permanent members of staff and a guest lecturer. As learning and thinking styles of different scholars formed part of the module it was decided to demonstrate the need for applying the principles of learning styles in practice actively. In this way learning opportunities promoted authentic learning. The innovation was met with much enthusiasm and appreciation as students realised that what they had experienced in class was exactly what they had to do in their practice once they were appointed as teachers.

\subsection{Taxation}

As with the engineering programmes, programmes in taxation also focus on applicable soft skills. Soft skills are to be found as pervasive competencies as outlined by the South African Institute of Chartered Accountants (SAICA 2010). These pervasive skills include taking a leadership position, becoming a reflective practitioner and a lifelong learner. Through curriculum development initiatives these pervasive skills are included in modules offered by the Department of Taxation. Although we have not yet conducted a conclusive study on curriculum change in this field, and thus do not report on it, innovation in facilitating and assessing learning is reflected on.

The Head of the Department of Taxation took the initiative to have her academic members of staff introduced to the construct of whole brain ${ }^{\circledR}$ learning and related learning theories. Informal workshops that focused on whole brain learning and action research were conducted.

One of the innovative ideas implemented was by a group of lecturers who challenged their students to design and print a booklet on taxation, and to design posters or games on taxation to explain basic taxation concepts to novices in laymen's terms.

A small-scale study on the application of the principles of whole brain ${ }^{\circledR}$ learning in taxation was executed by two lecturers. Their profiles reflected that they are opposites regarding thinking preferences. The profile of one lecturer shows that he has a preference for A and B quadrant thinking; the other lecturer's profile shows that she has a preference for the $\mathrm{C}$ and $\mathrm{D}$ quadrant. The innovative idea that emanated from their understanding of the profiles is that they decided to present a module on taxation as a pair for first-year students. The outcome of the study was initially reported at a conference (Hills \& Van Oordt 2012) and later reported under the title "Are two teachers better than one?" in an accredited journal on accounting research (Van Oordt, Van Oordt \& Du Toit 2014). 


\section{Conclusion}

In conclusion we would like the father of whole brain ${ }^{\circledast}$ thinking to have the last word (Herrmann 1998): experiences affirm that once the whole brain ${ }^{\otimes}$ concept is understood, whole brain ${ }^{\circledast}$ thinking becomes irresistible.

In terms of expanding the comprehensive model referred to in the introduction to this article, we realise that the focus must fall on intelligence per se. In addition to the construct 'whole brain ${ }^{\oplus}$ ' that is branded by Herrmann International, we will in addition refer to intelligent curriculum development, intelligent facilitating of learning, intelligent assessment, intelligent leadership and intelligent research.

Ultimately we claim that activating whole brain ${ }^{\circledast}$ innovation to nourish multiple intelligence is only a particle of the higher education cosmos. What we know at this point in time, what we consider now, what we engage in, what we apply and what we construct as new knowledge is only one of the small ripples on the water since we first engaged the whole brain $^{\circledast}$ pebble and tossed it into the ocean of our own scholarship of teaching practice and research.

Our research over many years that is reported to some extent in this article has made us firmly believe that becoming a whole brain ${ }^{\circledast}$ intelligent lecturer makes fertile soil for cultivating and nourishing intelligence in higher education. So, what we would like to leave the reader with is the challenge to consider the construct 'whole brain ${ }^{\circledR}$ intelligence'.

\section{List of references}

Bradberry, T. \& Greaves, J. 2009. Emotional intelligence 2.0. San Diego: Talent Smart.

De Boer, A., Du Toit, P.H., Scheepers, D.M. \& Bothma, T.J.D. 2013. Whole brain learning in higher education: Practice-based evidence. Oxford: Chandos.

De Jager, T. 2011. Beginner-teacher professional development: An action research approach to mentoring. MEd dissertation, University of Pretoria.

Du Toit, P.H. 2012. Using action research as process for sustaining knowledge production: A case study of a higher education qualification for academics. South African Journal of Higher Education, 26(6):1216-1233.

Du Toit, P.H. 2013. Social transformation starts with the self: An autobiographical perspective on the thinking style preferences of an educator. South African Journal of Education, 33(4):1-12.

Du Toit, P.H. 2014a. An auto-ethnographic lens on lecturer professional development. In Vandeyar, S. (Ed.) Good practice in culture-rich classrooms: Research-informed perspectives. (254-279) South Africa: Oxford.

Du Toit, P.H. 2014b. Framing higher education as a means to address the expectations of society using different frames (of mind). South African Journal of Higher Education, 28(3): 889-893.

Du Toit, P.H. 2015. Excellence in higher education: An auto-ethnographic journey of my contribution of educator professional development. EASA Conference: Celebrating excellence in education: A strong and enduring education system in the first 20 years of democracy, 11-14 January 2015, Legend Golf and Safari Resort, Mookgophong. 
Fringe, J. dos S.F. 2012. Promoting critical reflection for academic professional development in bigher education. $\mathrm{PhD}$ thesis, University of Pretoria.

Gardner, H. 1993. Multiple intelligences: The theory in practice. New York:Basic Books.

Herrmann, N. (Ed.) 1995. The creative brain, (2 $2^{\text {nd }}$ ed.) USA: Quebecor Printing Book Group.

Herrmann, N. 1996. The whole brain business book: Unblocking the power of whole brain thinking in organizations and individuals. New York: McGraw-Hill.

Herrmann, N. 1998. Twenty years of thinking about the thinking brain: A special summary of learning outcomes. Lake Lure: Herrmann International.

Herrmann-Nehdi, A. 2012. The best of both worlds: making blended learning really work by engaging the Whole Brain. Available at: http://www.hbdi.co.za/documents/Blending\%20learning.pdf

Hills, T. \& Van Oordt, M. 2012. Two teachers are better than one. Johannesburg Regional Conference of the Southern African Accounting Association, University of the Witwatersrand, 7 September.

Horak, E., Steyn, T.M. \& De Boer, A. 2001. A four quadrant whole brain approach in innovation and engineering problem solving to facilitate teaching and learning of engineering students. South African Journal of Higher Education, 15(3):202-9.

Hugo, J.F.M., Slabbert, J., Louw, J.M., Marcus, M., Bac, M., Du Toit, P.H. \& Sandars, J.E. 2012. The clinical associate curriculum - the learning theory underpinning the BCMP programme at the University of Pretoria. African Journal of Health Professions Education, 4(2):128-131.

Keller, J.M. 1987. Development and use of the ARCS model of motivational Design. Journal of Instructional Development, 10(3):2-10.

Knobbs, C. 2011. Employing small groups to promote independent learning and to develop social skills. Innovate, 6:44-5.

Kumar, R. 2014. Research methodology: A step-by-step guide for beginners. Los Angeles: SAGE.

Liebenberg, L. \& Mathews, E.H. 2012. Integrating innovation skills in an introductory engineering design-build course. International Journal of Technology and Design Education, 22:93-113.

Lumsdaine, E. \& Binks, M. 2005. Keep on moving! Entrepreneurial creativity and effective problem solving. Hightstown, NJ: McGraw-Hill Higher Education.

Lumsdaine, M. \& Lumsdaine, E. 1995. Thinking preferences of engineering students: Implications for curriculum restructuring, Journal of Engineering Education, 84(2):193204.

Lumsdaine, E., Lumsdaine, M. \& Shelnutt, J.W. 1999. Creative problem solving and engineering design. New York: College Custom Publication Group; McGraw-Hill Higher Education.

McNiff, J. \& Whitehead, J. 2006. All you need to know about action research. London: Sage.

Morris, R.J. 2006. Left brain, right brain, whole brain? An examination into the theory of brain lateralization, learning styles and the implications for education. PGCE thesis, Cornwall College, St. Austell.

TD, 11(2), November 2015, Special edition pp. 55-72. 
Mouton, J. 2001. How to succeed in your master's and doctoral studies: a South African guide and resource book. Pretoria: Van Schaik.

O'Leary, Z. 2014. The essential guide to doing your research project. London: SAGE.

Oosthuizen, M. 2001. An investigation into facilitating learning via the whole brain model in the study unit tooth morphology. MEd dissertation, University of Pretoria.

Proctor, T. 2010 Creative problem solving for managers: Developing skills for decision making and innovation. ( $3^{\text {rd }}$ ed.) New York: Routledge.

Pulko, S.H. \& Parikh, S. 2003. Teaching 'soft' skills to engineers. International Journal of Electrical Engineering Education, 40(4):243-54.

SAICA (South African Institute of Chartered Accountants). 2010. Competency framework: Guidance for academic programmes. Bruma: South African Institute of Chartered Accountants.

Slabbert, J.A., De Kock, D.M. \& Hattingh, A. 2009. The brave "new" world of education: Creating a new professionalism. Lansdowne: Juta.

Van de Ven, A.H. 1989. Nothing is quite so practical as a good theory. Academy of Management Review, 14(4):486-489.

Van Oordt, M. Van Oordt, T. \& Du Toit, P.H. 2014. Are two teachers better than one? Meditari Accountancy Research, 22(2):165-185.

Wolvaardt, J.E. \& Du Toit, P.H. 2015. Research supervision: A reciprocal meta-reflection. EASA Conference: Celebrating excellence in education: A strong and enduring education system in the first 20 years of democracy, 11-14 January 2015, Legend Golf and Safari Resort, Mookgophong.

Zuber-Skerritt, O. 2000. Action learning, action research and process management: theory, practice, praxis. Brisbane: Action Research Unit, Faculty of Education, Griffith University. 